\title{
The European Respiratory Society spirometry tent: a unique form of screening for airway obstruction
}

\begin{abstract}
Sara Maio*, Duane L. Sherrill*, William MacNee*, Peter Lange*, Ulrich Costabel*, Sven-Erik Dahlén*, Gerhard W. Sybrecht*, Otto C. Burghuber*, Robin Stevenson*, Philip Tønnesen*, Karl Haeussinger*, Gunilla Hedlin*, Torsten T. Bauer*, Josef Riedler*, Laurent Nicod*, Kai-Håkon Carlsen* and Giovanni Viegi*, on behalf of the European Respiratory Society/European Lung Foundation Spirometry Tent working group ${ }^{\#}$
\end{abstract}

ABSTRACT: In order to raise public awareness of the importance of early detection of airway obstruction and to enable many people who had not been tested previously to have their lung function measured, the European Lung Foundation and the European Respiratory Society (ERS) organised a spirometry testing tent during the annual ERS Congresses in 2004-2009.

Spirometry was performed during the ERS Congresses in volunteers; all participants answered a simple, brief questionnaire on their descriptive characteristics, smoking and asthma. Portable spirometers were freely provided by the manufacturer. Nurses and doctors from pulmonary departments of local hospitals/universities gave their service for free. Lower limit of normal (LLN) and Global Initiative for Chronic Obstructive Lung Disease (GOLD) criteria for diagnosing and grading airway obstruction were used.

Of 12,448 participants in six congress cities, 10,395 (83.5\%) performed acceptable spirometry (mean age $51.0 \pm 18.4$ yrs; $25.5 \%$ smokers; $5.5 \%$ asthmatic). Airway obstruction was present in $12.4 \%$ of investigated subjects according to LLN criteria and $20.3 \%$ according to GOLD criteria. Through multinomial logistic regression analysis, age, smoking habits and asthma were significant risk factors for airway obstruction. Relative risk ratio and $95 \%$ confidence interval for LLN stage I, for example, was $2.9(2.0-4.1)$ for the youngest age ( $\leqslant 19 \mathrm{yrs}), 1.9(1.2-3.0)$ for the oldest age ( $\geqslant 80$ yrs), 2.4 (2.0-2.9) for current smokers and 2.8 (2.2-3.6) for reported asthma diagnosis.

In addition to being a useful advocacy tool, the spirometry tent represents an unusual occasion for early detection of airway obstruction in large numbers of city residents with an important public health perspective.

KEYWORDS: Airway obstruction, general population, Global Initiative for Chronic Obstructive Lung Disease criteria, lower limit of normal criteria, screening

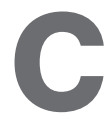
hronic obstructive pulmonary disease (COPD) has been described by the American Thoracic Society (ATS)/European Respiratory Society (ERS) guidelines on COPD [1] as a disease "characterised by airflow limitation that is not fully reversible".

COPD is one of the most important causes of mortality and morbidity worldwide; it represents the commonest cause of death from respiratory diseases, which are the third most common cause of death $(8 \%)$ in the 25 member states of the European Union (EU) [2]. However, these figures may be underestimated. According to the World Health Organization (WHO), COPD will become the third commonest cause of mortality [3] and the seventh commonest cause of disabilityadjusted life years worldwide by 2030 [4].

COPD represents a huge burden for healthcare systems and causes increasing costs for society due to absence from work, visits to the doctor's
AFFILIATIONS

*For affilation details, refer to the Acknowledgements section.

\#These contributors are listed in the Acknowledgements section.

CORRESPONDENCE

K-H. Carlsen

Dept of Paediatrics, Faculty of Medicine, University of Oslo Oslo University Hospital Oslo

NO 0027 Norway

E-mail: k.h.carlsen@medisin.uio.no

Received:

July 152010

Accepted after revision:

Nov 142011

First published online: Jan 202012 
clinic, medication and hospital admissions. The socioeconomic burden from COPD is also expected to increase. In Europe, direct/indirect costs of COPD were estimated at $\sim 38.7$ billion Euros in 2000 [5].

The growing burden of COPD is mainly due to the ageing of the world's population and to the continued use of tobacco [4]. Recently, the Burden of Obstructive Lung Disease (BOLD) Initiative measured the prevalence of COPD and its risk factors in 12 cities all over the world. Prevalence rates of Global Initiative for Chronic Obstructive Lung Disease (GOLD)defined COPD stage II or higher (forced expiratory volume in $1 \mathrm{~s}$ (FEV1)/forced vital capacity (FVC) $<0.70$ and FEV1 $<80 \%$ predicted) were $10.1 \%$ overall, $11.8 \%$ for males and $8.5 \%$ for females [6].

Within the Northern Ireland, Cost and Epidemiology of Chronic Obstructive Pulmonary Disease (NICECOPD) study on a general population sample in the Greater Belfast area, the prevalence of COPD varied from $4.9 \%$ (40-49 yrs) to $12.3 \%$ (60-69 yrs) in males and from $1.4 \%$ (40-49 yrs) to $4.5 \%$ (60$69 \mathrm{yrs}$ ) in females [7]. A Swedish study showed a prevalence of GOLD COPD of $14.3 \%$ [8]. A recent Polish study showed a prevalence of COPD, according to the lower limit of normality (LLN), of $15.3 \%$ in subjects aged $\geqslant 40$ yrs [9].

In recent years, some studies have evaluated the impact of different definitions of airway obstruction on the estimated prevalence of obstruction in general population samples, showing an overestimate of COPD using the GOLD criteria compared with the LLN criteria. Using the Third National Health and Nutrition Examination Survey (NHANES) data, CELLI et al. [10] showed a COPD prevalence of $18.4 \%$ according to the GOLD criteria and of $15.6 \%$ according to the LLN criteria. In the Korean NHANES survey, these results were confirmed: $10.9 \%$ with LLN criteria versus $15.5 \%$ with GOLD criteria [11].

Other studies also suggest an important association between COPD and asthma. In a prospective observational study, SILVA et al. [12] showed that subjects with active asthma, compared with nonasthmatics, had a 12.5 times higher risk of acquiring COPD [12]. Overlapping asthma and COPD prevalence rates in an Italian general population (proportional Venn diagram) were reported by VIEGI et al. [13].

Despite the high social and economic burden, COPD is an often underdiagnosed or misclassified disease. Many studies showed that spirometry is not commonly used for the diagnosis of COPD in primary care. In Sweden, only 30\% of subjects with a diagnosis of COPD in their medical records had undergone spirometry [14]. In the USA, analysis of medical records of patients admitted to academic tertiary care hospitals showed that only $31 \%$ of those with a COPD diagnosis had spirometry, by contrast $78 \%$ of subjects with congestive heart failure had echocardiography [15].

To overcome underdiagnosis and to prevent the development of severe stage of COPD, some screening programmes have been performed in the population at risk, showing prevalence values of COPD ranging from $\sim 20 \%$ to $\sim 47 \%$ [16-20].

Thus, the European Lung Foundation (ELF) Council and the ERS Executive Committee considered it worthwhile to ask us to analyse the data collected at the ELF/ERS spirometry tent during the annual ERS Congresses in 2004-2009, in order to increase the public awareness of airway obstruction and lung health. Moreover, the spirometry tent event had the aim of enabling many people, who had not been tested previously, to have their lung function measured so as to detect early cases of airway obstruction in the general population and to detect them potentially in early stage of airway obstruction.

\section{MATERIALS AND METHODS}

Every year, between 2004 and 2009, during the Annual Congress of the ERS, the ELF and the ERS organised a public spirometry event. This was usually performed in a public space, such as a railway station or a tent in a city square, to give local citizens the opportunity to have their lung function tested for free. Extensive media coverage leading up to the event helped to attract a large number of people.

During the six ERS Congresses in Glasgow (UK in 2004); Copenhagen (Denmark in 2005); Munich and Berlin (Germany in 2006 and 2008, respectively); Stockholm (Sweden in 2007) and Vienna (Austria in 2009), 12,448 volunteers decided freely to perform the spirometry and answered a simple brief questionnaire about their descriptive characteristics, smoking habits and asthma. The answers were manually entered into the spirometer's computer prior to performing the test.

Portable spirometers were freely provided by the manufacturer (NDD Medical Technologies, Zurich, Switzerland). Nurses and doctors from pulmonary departments of local hospitals/universities gave their service for free.

During all the events, lung function data were obtained using the NDD EasyOne Spirometer (NDD Medical Technologies), which is a hand-held, battery-operated device that uses an ultrasonic sensor to measure air flow. It was chosen for its level of accuracy and portability that meets published recommendations of the ERS and ATS, and because it does not require regular calibration [21]: indeed, the spirometer was not calibrated during the event. The potential stability of the calibration was one reason why this spirometer was selected for use in the BOLD and PLATINO (Proyecto Latinoamericano de Investigación en Obstrucción Pulmonar) studies [6, 22]. The humidity and the temperature were measured at the beginning of each event and the values inserted in the spirometer. Subjects performed the manoeuvre in a sitting position wearing a nose clip. The post-bronchodilation spirometric test was not performed.

Subjects with abnormal spirometry (abnormal curves or values) or people who had symptoms and were worried were given a letter addressed to their general practitioner suggesting further tests for possible confirmation of the findings and follow-up. Subjects could decide freely to take this letter to their general practitioner.

As confirmed by the data collectors, no change was performed in the software and outputs of the NDD EasyOne Spirometer. Available data were sent to the ELF Secretariat in Sheffield, UK, which forwarded them to the Pisa team (Pulmonary Environmental Epidemiology Unit, CNR Institute of Clinical Physiology, Pisa, Italy) for the statistical analyses. 
The LLN [23] was derived from population-specific prediction equations [24, 25]. Airway obstruction was reported if FEV1/ FVC was $<$ LLN $[10,11]$. The stage was defined by the level of FEV1 in \% pred (adjusted for age) [24]: stage I if FEV1 was $\geqslant 70 \%$ pred; stage II if $60 \% \leqslant \mathrm{FEV} 1<70 \%$ pred; stage III if $50 \%$ $\leqslant$ FEV $1<60 \%$ pred; stage IV if $35 \% \leqslant$ FEV $1<50 \%$ pred; and stage $\mathrm{V}$ if FEV1 $<35 \%$ pred [23]. Subjects with FEV1/FVC $\geqslant$ LLN were considered as nonobstructed.

To make comparisons with international studies possible, we also reported the prevalence of airway obstruction as defined by the fixed GOLD criteria $(\mathrm{FEV} 1 / \mathrm{FVC}<0.7)$ [26]. The stage was defined by level of FEV1 in \% pred (adjusted for age) [24]: stage I if FEV1 was $\geqslant 80 \%$ pred; stage II if $50 \% \leqslant \mathrm{FEV} 1<80 \%$ pred; stage III if $30 \% \leqslant \mathrm{FEV} 1<50 \%$ pred; and stage IV if FEV1 $<30 \%$ pred [26]. Subjects with FEV1/FVC $\geqslant 0.7$ were considered as nonobstructed.

Spirometries of F-quality grade were not considered in the analyses ( $n=2,053$, i.e. $16.5 \%$ of total participants).

Ethical approval was not sought since it was not a clinical trial and, after having been briefly instructed about the procedure and the meaning of the test, subjects freely decided to participate in the spirometry tent event. The protocol was approved by the ELF Council.

\section{Statistical analyses}

Analyses were performed using the Statistical Package STATA (Stata Statistical Software Release 9.0; StataCorp 2005, College Station, TX, USA).

The Chi-squared test was used to compare categorical variables and ANOVA to compare the mean values of continuous variables between groups.

In order to take into account the role of different risk factors, a multinomial regression analysis was performed by using the decades of age, smoking habits (smokers, ex-smokers or nonsmokers), sex and asthma (reported asthma symptoms, reported asthma diagnosis or nonasthma) as independent variables, and LLN severity categories (stage I, II, III or IV+) or GOLD severity categories (stage I, II or III+) as dependent variable. The choice to use the LLN IV+ category and GOLD III+ category is due to the small number of subjects in these severity levels.

\section{RESULTS}

12,448 volunteers were investigated during the ERS Congresses. Of these, 2,053 (16.5\%) performed spirometry with a quality grade equal F: these subjects had a mean age of $44.7 \pm 21.5$ yrs, $51.2 \%$ were males, $29.4 \%$ current smokers, $19.4 \%$ ex-smokers, $3.6 \%$ had asthma diagnosis and $3 \%$ had asthma symptoms; $67.7 \%$ performed at least three spirometric manoeuvres and $32.3 \%$ more than three manoeuvres.

$10,395(83.5 \%)$ performed spirometry with a quality grade above F: 826 resided in Glasgow, 1,039 in Copenhagen, 1,787 in Munich, 2,417 in Stockholm, 2,798 in Berlin and 1,528 in Vienna. The descriptive statistics showed a slightly higher frequency of females $(52.0 \%)$ and a mean age of $51.0 \pm 18.4 \mathrm{yrs}$, with the lowest mean age in Berlin (table 1). Stratifying the sample in decades of age, the most numerous age classes were 40-49 yrs, 50-59 yrs and 60-69 yrs (table 1). The prevalence of smokers was $25.5 \%$ (maximum in Copenhagen, $51.4 \%$ ) and of ex-smokers was $27.1 \%$ (maximum in Glasgow, 31.5\%) (table 1). There was a prevalence of $5.5 \%$ both for reported asthma symptoms (maximum in Stockholm, 7.7\%) and asthma diagnosis (maximum in Glasgow, 7.4\%) (table 1). As regards the spirometry quality grade, the highest values of quality $\mathrm{A}$ were in Glasgow (41.2\%), Copenhagen (36.1\%) and Vienna (30.4\%) (table 1).

Overall, $12.4 \%$ of participating subjects had a prevalence of airway obstruction as defined by LLN stage I+, ranging from $10.2 \%$ in Vienna to $15.6 \%$ in Copenhagen. Considering the individual LLN categories, the highest prevalence rates were: stage I in Berlin (8.8\%); stage II in Glasgow (3.3\%); stage III in Glasgow and Copenhagen (1.3\%); stage IV in Copenhagen and Stockholm (1.5\%); and stage V in Copenhagen (1.4\%) (table 2).

The overall prevalence of airway obstruction as defined by GOLD stage I+ was $20.3 \%$ with a range from $16.4 \%$ in Berlin to $25.4 \%$ in Copenhagen. Considering the individual GOLD categories, the highest prevalence rates were: stage I in Munich (12.6\%) and stages II, III and IV in Copenhagen $(11.1 \%, 1.9 \%$ and $1.1 \%$, respectively) (table 2$)$.

The use of the GOLD criteria instead of the LLN yielded an overestimate of airway obstruction of $\sim 64 \%$ in the overall sample. Considering the severity levels, the GOLD criteria overestimated mild-to-moderate stages whilst it yielded similar values to LLN criteria in severe-to-very severe stages.

Further analyses were performed to compare the descriptive characteristics and the presence of asthma in the whole sample through the LLN categories (table 3) and the GOLD categories (online supplementary table S1).

Regarding the LLN categories, females had a significantly higher prevalence of LLN I (8.6\%) and LLN III (1.3\%), whilst males had a higher prevalence of LLN II (2.1\%) and LLN IV+ (1.8\%). Subjects with LLN I had the lowest mean age and those with LLN III had the highest mean age. Stratifying by decades of age, the oldest age groups showed a higher prevalence of all the LLN categories (stage II and IV+ in the decade 70-79 yrs and stage III in subjects with age $\geqslant 80 \mathrm{yrs}$ ), except for LLN stage I, which was higher in subjects aged $\leqslant 19$ yrs (table 3 ). These youngest subjects had a mean age of $14.7 \pm 3.9 \mathrm{yrs}, 23.0 \%$ were current smokers, 3.9\% ex-smokers, 6.6\% had asthma diagnosis and $3.7 \%$ had asthma symptoms (data not shown).

Smokers, ex-smokers and subjects with reported asthma symptoms or diagnosis had higher prevalence rates in all the LLN categories: in particular, LLN stage I for smokers and exsmokers (10.6\% and $7.6 \%$, respectively) and for subjects with reported asthma symptoms and asthma diagnosis $(7.8 \%$ and $14.9 \%$, respectively) (table 3 ).

Regarding the GOLD categories, higher values of prevalence rates of all the analysed variables were found except for GOLD stage III+ (online supplementary table S1).

Figure 1 describes the association between airway obstruction, age and smoking habits. Among smokers, the prevalence of airway obstruction increased from 40-49 yrs of age upwards, reaching a value of $29 \%$ at $70-79$ yrs using the LLN criteria and a value of $68 \%$ at age $\geqslant 80$ yrs using the GOLD criteria. Among ex-smokers, the prevalence of airway obstruction increased 
TABLE 1 Descriptive characteristics of participating subjects by countries

\begin{tabular}{|c|c|c|c|c|c|c|c|c|}
\hline Subjects n & 826 & 1039 & 1787 & 2417 & 2798 & 1528 & 10395 & \\
\hline Females & 49.0 & 50.8 & 55.6 & 54.2 & 49.1 & 52.4 & 52.0 & $<0.001$ \\
\hline Males & 51.0 & 49.2 & 44.4 & 45.8 & 50.9 & 47.6 & 48.0 & \\
\hline Age yrs & $50.9 \pm 15.7$ & $53.0 \pm 17.6$ & $58.6 \pm 16.2$ & $53.2 \pm 17.3$ & $40.8 \pm 18.0$ & $56.0 \pm 17.4$ & $51.0 \pm 18.4$ & $<0.001$ \\
\hline 20-29 & 9.3 & 10.3 & 6.5 & 10.7 & 20.9 & 7.5 & 12.1 & \\
\hline $30-39$ & 13.4 & 13.0 & 7.3 & 10.2 & 14.0 & 8.1 & 11.0 & $<0.001$ \\
\hline $40-49$ & 20.7 & 13.1 & 10.8 & 13.9 & 19.5 & 14.9 & 15.4 & \\
\hline $50-59$ & 23.1 & 19.3 & 17.0 & 20.7 & 13.6 & 17.4 & 17.7 & \\
\hline $60-69$ & 19.1 & 23.7 & 32.2 & 25.2 & 13.5 & 27.0 & 22.9 & \\
\hline Ex-smokers & 31.5 & 20.6 & 28.3 & 30.4 & 22.7 & 30.5 & 27.1 & \\
\hline Smokers & 27.1 & 51.4 & 17.7 & 20.0 & 27.2 & 21.9 & 25.5 & \\
\hline \multicolumn{9}{|l|}{ Asthma } \\
\hline Nonasthmatic & 87.8 & 91.0 & 86.7 & 85.3 & 91.0 & 92.8 & 89.0 & $<0.001$ \\
\hline Symptoms & 4.8 & 5.7 & 7.1 & 7.7 & 3.8 & 3.7 & 5.5 & \\
\hline Diagnosis & 7.4 & 3.3 & 6.2 & 7.0 & 5.2 & 3.5 & 5.5 & \\
\hline Subjects ${ }^{\#}$ n & 888 & 1187 & 1978 & 2820 & 3918 & 1657 & 12448 & \\
\hline \multicolumn{9}{|l|}{ Quality grades ${ }^{\pi}$} \\
\hline $\mathrm{F}$ & 7.0 & 12.5 & 9.6 & 14.3 & 28.6 & 7.8 & 16.5 & \\
\hline D & 21.1 & 27.8 & 32.5 & 33.1 & 39.0 & 30.1 & 33.0 & $<0.001$ \\
\hline C & 20.5 & 16.9 & 23.6 & 21.6 & 17.8 & 18.3 & 19.7 & \\
\hline
\end{tabular}

Data are presented as $\%$ or mean \pm SD, unless otherwise stated. ${ }^{\#}$ : with quality grades; ${ }^{\circ}$ : Chi-squared test was performed to compare F and (A-B-C-D) quality grades by country; the results showed a p-value $<0.001$.

from $60-69$ yrs of age upwards, reaching a value of $27 \%$ at age $\geqslant 80$ yrs using the LLN criteria, and increased from 40-49 yrs of age upwards, reaching a value of $51 \%$ at age $\geqslant 80$ yrs using the GOLD criteria. Nonsmokers showed an increase in the prevalence of airway obstruction at age $\geqslant 70 \mathrm{yrs}$, reaching a value of $11 \%$, using the LLN criteria, and an increase from 60 69 yrs of age upwards, reaching a value of $40.0 \%$ at age $\geqslant 80$ yrs using the GOLD criteria. Overall, figure 1 showed that, using the GOLD criteria instead of the LLN criteria, airway obstruction was underestimated until the decade 3039 yrs and overestimated starting with the decade 40-49 yrs.

Multinomial logistic regression analysis was used to determine significant risk factors for the degree of airway obstruction as measured by each LLN stage (table 4), and GOLD stage (online supplementary table S2), included as the dependent variable; decades of age, sex, smoking habits and asthma were the independent variables. The spirometry quality grades were not included in the analysis because they did not show a significant association with the dependent variable.

Considering the LLN criteria, males had a significantly lower RRR to develop stage I (RRR 0.7, 95\% CI 0.6-0.8) with respect to females. The youngest age group had a significantly higher RRR for LLN stage I (RRR 2.9, 95\% CI 2.0-4.1). The oldest age groups had a significant RRR of having higher severity levels of airway obstruction: RRR 5.6 (95\% CI 2.9-11.0) for stage II and RRR 6.5 (95\% CI 3.3-12.7) for stage IV+ in the decade 7079 yrs and RRR 20.3 (95\% CI 6.5-63.0) for stage III in subjects with age $\geqslant 80$ yrs. Ex- and current smokers showed significantly increased risks in all LLN categories, with the highest RRR in the LLN stage III (RRR 3.0, 95\% CI 1.9-4.7, and RRR 4.0, 95\% CI 2.4-6.6, respectively). Analogous figures were shown for reported asthma symptoms and asthma diagnosis with the highest RRR in LLN stage III (RRR 4.3, 95\% CI 2.6-7.2, and RRR 5.3, 95\% CI 3.1-9.0, respectively) (table 4).

Considering the GOLD criteria, a different trend for age with stage I was found: lower values of RRR for subjects $\leqslant 19$ yrs of age, much higher RRR values for older decades and the highest values for 70-79 yrs (RRR 10.9, 95\% CI 7.6-15.8) and $\geqslant 80 \mathrm{yrs}$ (RRR 16.6, 95\% CI 10.8-25.5); by contrast, a similar trend for smoking and asthma was found. With respect to stages II and III+, analogous figures were shown with higher RRR, especially for age (online supplementary table S2). 
TABLE 2 Prevalence of airway obstruction categories by countries

\begin{tabular}{|c|c|c|c|c|c|c|c|c|}
\hline & Glasgow & Copenhagen & Munich & Stockholm & Berlin & Vienna & Total & p-value \\
\hline Subjects $n$ & $825^{\#}$ & $1037^{\#}$ & $1781^{\#}$ & 2417 & $2795^{\#}$ & $1526^{\#}$ & $10381^{\#}$ & \\
\hline Stage I & 8.7 & 8.7 & 6.1 & 7.0 & 8.8 & 5.8 & 7.5 & $<0.001$ \\
\hline Stage II & 3.3 & 2.7 & 1.7 & 1.6 & 1.9 & 2.0 & 2.0 & \\
\hline Stage III & 1.3 & 1.3 & 1.2 & 1.1 & 1.0 & 1.2 & 1.1 & \\
\hline Stage I+ & 15.5 & 15.6 & 10.5 & 11.5 & 13.3 & 10.2 & 12.4 & \\
\hline \multicolumn{9}{|l|}{ GOLD $^{+}$} \\
\hline Stage I & 11.4 & 11.3 & 12.6 & 10.0 & 8.4 & 11.0 & 10.4 & $<0.001$ \\
\hline Stage II & 10.6 & 11.1 & 7.3 & 8.2 & 6.4 & 8.0 & 8.0 & \\
\hline Stage III & 1.5 & 1.9 & 1.3 & 1.7 & 1.4 & 1.1 & 1.5 & \\
\hline Stage IV & 0.7 & 1.1 & 0.3 & 0.2 & 0.2 & 0.3 & 0.4 & \\
\hline
\end{tabular}

Data are presented as \%, unless otherwise stated. LNN: lower limit of normal; GOLD: Global Initiative for Chronic Obstructive Lung Disease. ${ }^{\#}$ : some subjects had some missing information about lung function. ": American Thoracic Society/European Respiratory Society criteria: forced expiratory volume in $1 \mathrm{~s}$ (FEV1)/forced vital capacity $(\mathrm{FVC})<$ LLN. Stage I: FEV $1 \geqslant 70 \%$ predicted; stage II: $60 \% \leqslant$ FEV $1<70 \%$ pred; stage III: $50 \% \leqslant$ FEV $1<60 \%$ pred; stage IV: $35 \% \leqslant=F E V_{1}<50 \%$ pred; and stage V: FEV $1<35 \%$ pred. ${ }^{+}$: GOLD criteria: FEV1/FVC $<70 \%$. Stage I: FEV $1 \geqslant 80 \%$ pred; stage II: $50 \% \leqslant$ FEV $1<80 \%$ pred; stage III: $30 \% \leqslant$ FEV $<50 \%$ pred; and stage IV: FEV 1 $<30 \%$ pred.

\section{DISCUSSION}

The ELF/ERS spirometry tent, as well as being an important advocacy tool, turned out to be a unique way of screening for early detection of airway obstruction, permitting many people, who had not been tested previously, to have their lung function measured. It should be pointed out that it was not an aim of this event to provide information on COPD or asthma diagnoses, as this can only be made by clinicians upon

TABLE 3 Lower limit of normal (LLN) percentages in the overall sample by sex, age, smoking habit and asthma

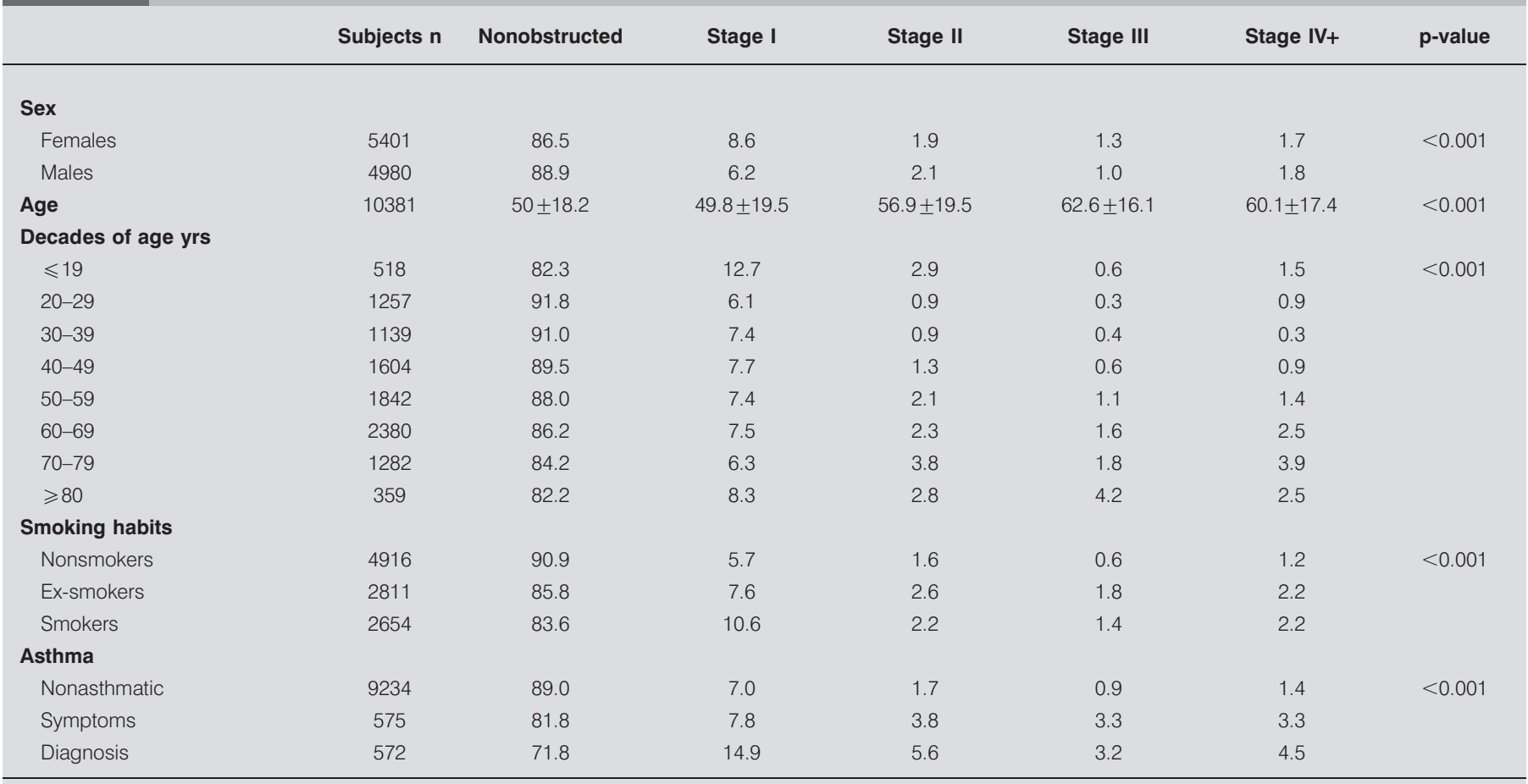

Data are presented as \% or mean $\pm \mathrm{SD}$, unless otherwise stated. American Thoracic Society/European Respiratory Society criteria: forced expiratory volume in $1 \mathrm{~s}$ (FEV 1 )/ forced vital capacity $<$ LLN. Stage I: FEV $1 \geqslant 70 \%$ predicted; stage II: $60 \% \leqslant$ FEV $1<70 \%$ pred; stage III: $50 \% \leqslant=F E V_{1}<60 \%$ pred; and stage IV+: FEV $1<50 \%$ pred. 


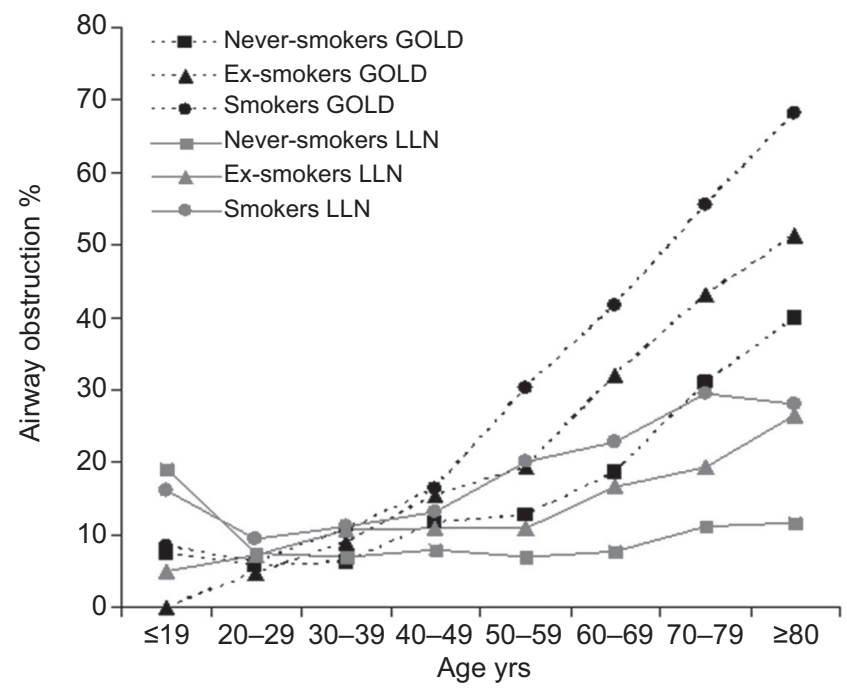

FIGURE 1. Airway obstruction prevalence by smoking habits by decades of age. GOLD: Global Initiative for Chronic Obstructive Lung Disease; LLN: Iower limit of normal.

integration of medical history, physical examination and objective tests. This is not possible from simple questionnaires and pre-bronchodilator spirometry, as was performed in the spirometry tent event. Although this was an observational account of a public health promotion effort rather than a standard scientific study, the prevalence rates of airway obstruction detected with the spirometry tent using the LLN criteria $(12.4 \%)$ and the GOLD criteria $(20.3 \%)$ were very close to the median values (fig. 2) of the results of other scientific studies performed in several countries.

The BOLD Initiative reported a prevalence rate of GOLDdefined COPD stage II+ of $10.1 \%$ considering 12 cities around the world; the value of GOLD stage I+ was 19.3\% (computed from table 3 in [6]). In the NHANES survey, CELLI et al. [10] measured a prevalence rate of $18.4 \%$ (GOLD criteria stage I+) and of $15.6 \%$ (LLN criteria stage $\mathrm{I}+$ ) in a general adult population sample. In the Korean National Health and Nutrition Examination Survey (NHANES) survey, prevalence rates of $15.5 \%$ (GOLD criteria stage I+) and of $10.9 \%$ (LLN criteria stage I+) were measured [11].

In Poland, spirometric screening to early detect COPD in highrisk populations $(n=11,027)$ was performed. Airway obstruction was found in $24.3 \%$ of the subjects reaching a value of $30.6 \%$ in smokers aged $\geqslant 40$ yrs with a smoking history of $>10$ pack-yrs [19]. The study then continued with a total of 110,355 subjects (aged 53.5 $\pm 11.5 \mathrm{yrs}$ ), of whom 64\% were current smokers, $25.1 \%$ former smokers and $10.9 \%$ lifelong nonsmokers. In total, $20.3 \%$ had airway obstruction [20], i.e. the same value we found from the ERS spirometry tent data.

Other screening studies have been performed primarily in populations at risk, such as smokers. In a primary care setting in Sweden, 27\% $(n=512)$ of the smokers (aged $40-55 \mathrm{yrs}$ ) demonstrated airway obstruction [27]. In a primary care setting in the Netherlands, $29.9 \%(n=805)$ of the smokers (aged 40-65 yrs) had airway obstruction [16]. Similar findings were found in Israel, where 1,058 adults aged 45-75 yrs with a

\begin{tabular}{|c|c|c|c|c|}
\hline \multirow[t]{3}{*}{ TABLE 4} & \multicolumn{4}{|c|}{ Results of multinomial logistic regression } \\
\hline & \multicolumn{4}{|c|}{ LLN stage } \\
\hline & $\mathbf{I}$ & II & III & IV+ \\
\hline \multicolumn{5}{|l|}{ Sex } \\
\hline Females & 1.0 & 1.0 & 1.0 & 1.0 \\
\hline Males & $0.7(0.6-0.8)$ & $1.1(0.9-1.5)$ & $0.7(0.5-1.1)$ & $1.1(0.8-1.5)$ \\
\hline \multicolumn{5}{|l|}{$\begin{array}{l}\text { Decades of } \\
\text { age yrs }\end{array}$} \\
\hline 20-29 & 1.0 & 1.0 & 1.0 & 1.0 \\
\hline$\leqslant 19$ & $2.9(2.0-4.1)$ & $4.6(2.1-10.2)$ & $3.1(0.7-14.0)$ & $2.6(1.0-6.7)$ \\
\hline 30-39 & $1.3(0.9-1.8)$ & $1.0(0.4-2.4)$ & $1.2(0.3-4.7)$ & $0.4(0.1-1.3)$ \\
\hline $40-49$ & $1.3(1.0-1.8)$ & $1.5(0.7-3.2)$ & $2.0(0.6-6.6)$ & $1.1(0.5-2.3)$ \\
\hline $50-59$ & $1.3(1.0-1.7)$ & $2.5(1.3-4.9)$ & $3.5(1.2-10.4)$ & $1.7(0.8-3.5)$ \\
\hline $60-69$ & $1.4(1.1-1.9)$ & $3.0(1.5-5.7)$ & $5.8(2.0-16.5)$ & $3.5(1.8-6.7)$ \\
\hline $70-79$ & $1.4(1.0-1.9)$ & $5.6(2.9-11.0)$ & $7.9(2.7-23.3)$ & $6.5(3.3-12.7)$ \\
\hline$\geqslant 80$ & $1.9(1.2-3.0)$ & $4.3(1.8-10.5)$ & $20.3(6.5-63.0)$ & $4.5(1.8-11.2)$ \\
\hline \multicolumn{5}{|l|}{$\begin{array}{l}\text { Smoking } \\
\text { habits }\end{array}$} \\
\hline Nonsmokers & 1.00 & 1.00 & 1.00 & 1.00 \\
\hline Ex-smokers & $1.6(1.3-1.9)$ & $1.8(1.3-2.5)$ & $3.0(1.9-4.7)$ & $1.9(1.3-2.7)$ \\
\hline Smokers & $2.4(2.0-2.9)$ & $2.3(1.6-3.2)$ & $4.0(2.4-6.6)$ & $3.2(2.1-4.6)$ \\
\hline \multicolumn{5}{|l|}{ Asthma } \\
\hline Nonasthmatic & 1.00 & 1.00 & 1.00 & 1.00 \\
\hline Symptoms & $1.3(0.9-1.7)$ & $2.6(1.6-4.1)$ & $4.3(2.6-7.2)$ & $2.7(1.6-4.4)$ \\
\hline Diagnosis & $2.8(2.2-3.6)$ & $4.7(3.2-7.1)$ & $5.3(3.1-9.0)$ & $4.8(3.1-7.4)$ \\
\hline
\end{tabular}

Data are presented as \% or relative risk ratio (95\% confidence interval), unless otherwise stated. American Thoracic Society/European Respiratory Society criteria: forced expiratory volume in $1 \mathrm{~s}$ (FEV 1 )/forced vital capacity < lower limit of normal. Stage I: FEV $1 \geqslant 70 \%$ predicted; stage II: $60 \% \leqslant F E V_{1}<70 \%$ pred; stage III: $50 \% \leqslant F E V_{1}<60 \%$ pred; and stage IV+: FEV1 $<50 \%$ pred.

history of at least 20 pack-yrs cigarette smoking were screened for airway obstruction, and a prevalence of $22.2 \%$ was reported [17]. In a primary care setting in Belgium, screening by spirometry showed a $46.6 \%$ prevalence of airway obstruction in current smokers (aged 40-70 yrs; $n=146$ ), of which $29.5 \%$ were newly detected [18]. A quite different screening programme was performed in Barcelona (Spain) in 100 pharmacy customers (aged $>40 \mathrm{yrs}$ ) with respiratory symptoms and/or a history of smoking; they were invited to perform spirometry and $24 \%$ demonstrated airway obstruction [28].

To compare our data with those of previously described screening studies we have assessed the presence of airway obstruction in smokers aged $\geqslant 40$ yrs: the ELF/ERS spirometry tent data $(31.9 \%)$ showed a result very close to the median value reported in figure $2(29.9 \%)$. Our data also confirmed the association of airway obstruction, computed using either the LLN or the GOLD criteria, with previously reported risk factors such as sex, age, smoking and asthma.

Concerning sex, there were different results using the LLN or GOLD criteria: the GOLD criteria showed a higher risk of having airway obstruction among males compared with females (RRR 1.3 for stage II), confirming findings of recent studies. A study performed in subjects aged $\geqslant 55$ yrs living in 


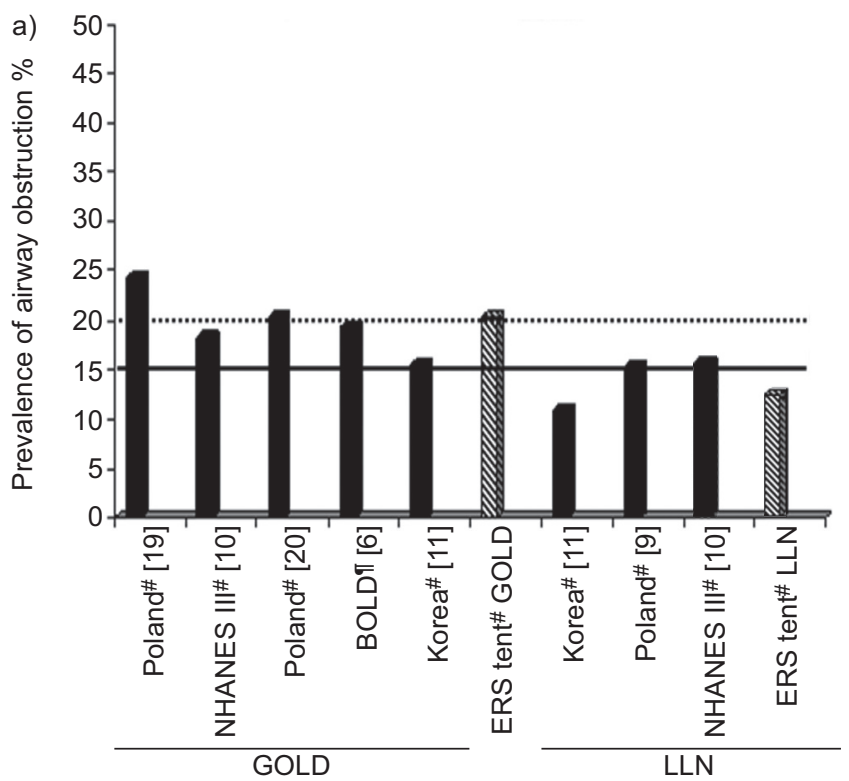

b)

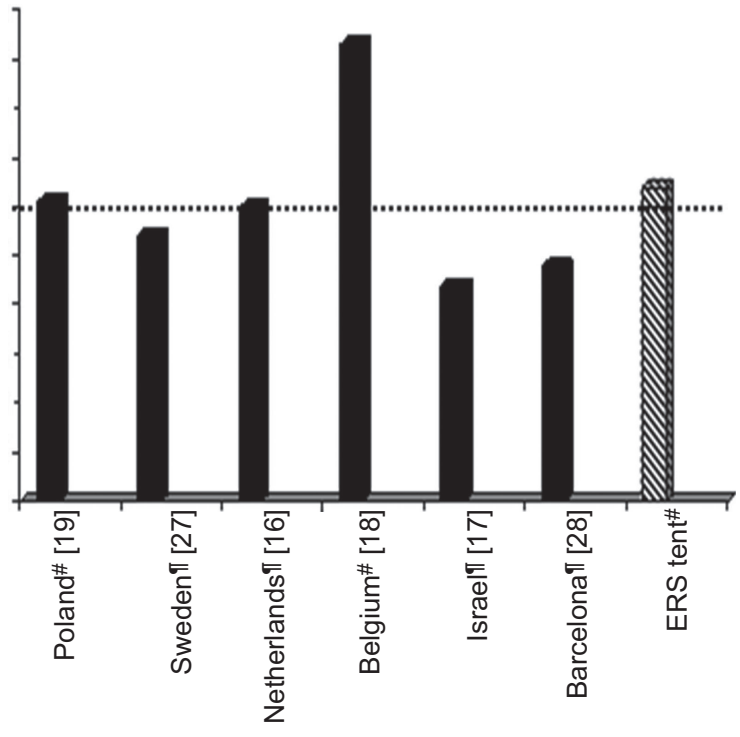

FIGURE 2. Prevalence of airway obstruction in a) the general population and b) smokers aged $\geqslant 40 \mathrm{yrs}$. In the general population, the prevalence values ranged from $15.5 \%$ to $24.3 \%$, with a median value of $19.8 \%$ (Global Initiative for Chronic Obstructive Lung Disease (GOLD); .......) and from $10.9 \%$ to $15.6 \%$, with a median value of $15.3 \%$ (lower limit of normal (LLN); —_ ). In smokers, the prevalence values range from $22 \%$ to $46.6 \%$, with a median value of 29.9\% (GOLD criteria). NHANES: National Health and Nutrition Examination Survey; ERS: European Respiratory Society. "*: spirometric test without bronchodilator; " : spirometric test with bronchodilator.

Rotterdam, the Netherlands, found a hazard ratio of $1.6(95 \%$ CI, 1.4-2.2) in males for the development of COPD, adjusted for age and smoking habits, in comparison to females [29]. Other studies have also shown a higher prevalence of COPD in males with respect to females [7, 22], although there are reports which contradict these data [30]. Using the LLN criteria, our data also showed a protective effect in males for stage I. This might be due to a different susceptibility to the deleterious effects of tobacco smoking by sex, as reported by other authors [30]. Indeed, females in stage I had a significantly higher prevalence of smoking habit with respect to males, which did not occur in the other severity levels (data not shown). A possible explanation could be that female smokers have a higher prevalence of bronchial hyperresponsiveness than males, a well known risk factor for developing airway obstruction. In addition, at the same level of smoking history, females may be more likely to develop obstruction than males [30].

Our findings also suggest an increased risk of developing airway obstruction in older age with the highest value at $\geqslant 80$ yrs of age, reaching a prevalence of $27 \%$ and $51 \%$ in exsmokers (LLN and GOLD, respectively) and of $28 \%$ and $68 \%$ in smokers (LLN and GOLD, respectively) (fig. 1).

Interestingly, our data showed a non-negligible prevalence of LLN stage I $(12.7 \%)$ in subjects aged $\leqslant 19$ yrs and of GOLD stage I $(8.3 \%)$ in subjects aged $40-49$ yrs, indicating the need to start screening for airway obstruction at a younger age than previously thought. Recently, using the European Community Respiratory Health Survey database, De MARCO et al. [31] showed that, in subjects with airway obstruction, respiratory symptoms (chronic cough or phlegm and/or dyspnoea) were associated with accelerated lung function decline only among smokers, suggesting that young symptomatic smokers with mild-to-moderate airway obstruction represent a high-risk subgroup [31].
Our results confirmed an increased risk of having airway obstruction among smokers and ex-smokers. In the 1970s, it was estimated that $15-20 \%$ of smokers develop COPD [32]. More recently, in a longitudinal Swedish study, LINDBERG et al. [8] reported prevalence rates of COPD of $24.6 \%$ in smokers, $14.5 \%$ in ex-smokers and $7.8 \%$ in nonsmokers, reaching values of 50, 33 and $21 \%$, respectively, in elderly subjects (76-77 yrs).

Our data also demonstrated a strong relationship between airway obstruction and patient-reported asthma diagnosis (RRR 5.3 for LLN stage III and RRR 5.5 for GOLD stage III+); these results are consistent with those of SILVA et al. [12] who, in a prospective observational study, showed that subjects with active asthma had a 12.5-times-higher risk of acquiring COPD compared with nonasthmatics. This is also in line with the recently reported finding that childhood asthma in males gave an odds ratio for COPD in adult age of 10.48 versus 3.74 in females, both values higher than for smokers [33].

A comorbid relationship between asthma and airway obstruction has been shown from the estimation of overlapping prevalence in the general population (proportional Venn diagram). VIEGI et al. [13] quantified the proportion of the general population with obstructive lung disease (OLD) and the intersections of physician-diagnosed asthma, chronic bronchitis and emphysema in two Italian general population samples compared with airway obstruction determined by spirometry. Approximately $18 \%$ of the Italian general population reported either the presence of OLD or showed spirometric signs of airway obstruction. Furthermore, asthma, chronic bronchitis and emphysema largely coexisted [13].

\section{Comparison between LLN and GOLD criteria}

Our data confirmed that the use of a fixed ratio (FEV1/FVC $<0.7)$ can lead to an overestimation of airway obstruction: 
overall, using the GOLD criteria compared with the LLN, there was an overestimation of airway obstruction of $\sim 64 \%(20.3 \%$ versus $12.4 \%$ ). In particular, the GOLD criteria overestimated the mild-to-moderate stages when considering the severity levels; however, it was comparable to LLN criteria in severe-tovery severe stages. VIEGI et al. [34] had already shown, in 2000, that the fixed ratio criteria with respect to the ERS criteria for airway obstruction overestimates the prevalence of airway obstruction (18\% versus $11.3 \%$ ). They also indicated that the GOLD criteria had higher sensitivity but lower specificity for reported symptoms/disease than the ERS criteria [34].

Moreover, our findings indicate that using the GOLD criteria overestimates airway obstruction in the oldest subjects and underestimates airway obstruction in the youngest subjects with respect to the ATS/ERS recommended criteria, as reported by other authors [10, 20, 35]. In particular, using the GOLD criteria compared with the LLN, airway obstruction was underestimated until the decade 30-39 yrs and overestimated starting with the decade $40-49$ yrs (fig. 1).

\section{Weaknesses of the study}

A possible weakness of this study was the use of different teams that did not perform a common spirometry training event; this aspect might have caused a wide variability of the results in the different countries. In reality, the variability between countries seemed to be due to different anthropometric features.

The use of the prediction equations from the European Community for Coal and Steel (ECCS) [24] to derive the LLN might have underestimated FEV1 and FVC predicted values, as reported by other authors [36]. However, it should be pointed out that ECCS equations were derived from old data collected from a number of different studies, using different methods and from different populations [36]. Conversely, these prediction equations, at present, are the most widely used in Europe, facilitating international comparisons of our results.

It should be taken into account that in the ELF/ERS spirometry tent the post-bronchodilation spirometric test was not performed, which could also give an overestimation of airway obstruction. In a random population sample in Norway, JOHANNESSEN et al. [37] estimated that the prevalence of GOLD-defined COPD (with bronchodilation) was 27\% lower than COPD defined without bronchodilatation $(7.0 \%$ and $9.6 \%$, respectively) [37]. Applying this reduction factor to our results meant that prevalence of LLN airway obstruction would be $9.1 \%$ and of GOLD airway obstruction would be $14.8 \%$; extremely relevant values from a public health perspective.

\section{Strengths of the study}

The main strength of this study was the large sample size $(n=10,395)$; indeed no other European study reached this number of investigated subjects, with the exception of the Polish spirometric screening study $(n=110,355)$ [20]. Moreover, the same spirometer was used during all the events, an instrument already selected for use in the BOLD and PLATINO studies.

Although this was not a standard scientific study, the prevalence of airway obstruction obtained with the spirometry tents was very close to the median value obtained by ad hoc organised scientific studies; thus, these results have highlighted the usefulness of detecting airway obstruction in large numbers of city residents during large awareness initiatives. These initiatives enabled many people who had not been tested previously to have their lung function measured and to eventually identify early cases of airway obstruction. An early detection would permit prevention of the severe forms of the disease by implementing, for example, early smoking cessation and appropriate treatment.

Additionally, our data contribute further evidence towards the recent debate over the use of LLN or GOLD criteria [38, 39].

The ELF/ERS spirometry tent is illustrative of the worldwide effort to increase the awareness of airway obstruction among the public, the media and policy makers, carried out by the WHO and partners (respiratory, allergological and general practitioner societies, patients and governmental organisations) within the Global Alliance against chronic Respiratory Diseases (GARD) [4, 40], which followed on from the publication by the ELF and ERS of the European Lung White Book in 2003 [5]. The ERS is now preparing the second edition of the European Lung White Book, which can foster new opportunities offered by the EU for research on chronic respiratory diseases [41]. The Forum of International Respiratory Society (FIRS) launched an awareness campaign called "2010: the Year of the Lung" (www.yearofthelung.org). October 14, 2010, designated as World Spirometry Day, has been a further occasion to test the screening properties of such a large awareness initiative.

\section{Conclusions}

Besides being an useful advocacy tool for ELF and ERS, the spirometry tent represented an unique opportunity to detecting airway obstruction in large numbers of city residents, yielding prevalence rates and associations with risk factors for airway obstruction consistent with standard scientific surveys.

Moreover, the results of this study confirm the importance of spirometry screening for young smokers with respiratory symptoms. The identification of early cases of airway obstruction might help target early smoking cessation, the most important action proven to reduce risk of developing severe disease.

\section{STATEMENT OF INTEREST}

Statements of interest for W. MacNee and P. Lange, and for the study itself can be found at www.erj.ersjournals.com $/ \mathrm{site} / \mathrm{misc} /$ statements. xhtml

\section{ACKNOWLEDGEMENTS}

Affiliation for authors are as follows. S. Maio: Pulmonary Environmental Epidemiology Unit, CNR Institute of Clinical Physiology, Pisa, Italy; D.L. Sherrill: College of Public Health, University of Arizona, Tucson, AZ, USA; W. MacNee: Dept of Medical and Radiological Sciences, ELEGI Colt Research Laboratories, MRC/UoE Centre for Inflammation Research, Queen's Medical Research Institute, University of Edinburgh, Edinburgh, UK; P. Lange: Dept of Cardiology and Pulmonary Medicine, Hvidovre Hospital, Hvidovre, Denmark; U. Costabel: Ruhrlandklinik and Medical Faculty, University of Duisburg-Essen, Essen, Germany; S-E. Dahlén, Karolinska Institutet, Centre for Allergy Research, Stockholm, Sweden; G.W. Sybrecht: Innere Medizin V, Universitätsklinikum des Saarlandes, Homburg/ Saar, Germany; O.C. Burghuber: Otto Wagner Hospital, Vienna, Austria; R. Stevenson: Dept of Respiratory Medicine, Queen 
Elizabeth Building, Glasgow Royal Infirmary, Glasgow, UK; P. Tønnesen, Dept of Pulmonary Diseases, Genofte University Hospital, Genofte, Denmark; K. Haeussinger, Lungen und Bronchialheilkunde Asklepios Fachkliniken, Gauting, Germany; G. Hedlin, Astrid Lindgren Children's Hospital, Karolinska Institutet and Karolinska University Hospital, Stockholm, Sweden; T.T. Bauer, Dept of Pneumology Respiratory Diseases Clinic "Heckeshorn", Berlin, Germany; J. Riedler, Children's Hospital SchwarzachKardinal, Schwarzach, Austria; L. Nicod: Centre Hospitalier Universitaire Vaudois (CHUV), Faculté de Biologie et de Médecine, Lausanne, Switzerland; K-H. Carlsen: Dept of Paediatrics, Faculty of Medicine, University of Oslo, Oslo University Hospital, Oslo, Norway; G. Viegi: Pulmonary Environmental Epidemiology Unit, CNR Institute of Clinical Physiology, Pisa and the Institute of Biomedicine and Molecular Immunology "A. Monroy", CNR, Palermo, Italy.

The ERS/ELF Spirometry Tent working group is as follows: E.F. Hansen (Dept of Cardiology and Pulmonary Medicine, Hvidovre Hospital, Hvidovre, Denmark), T. Blum (Dept of Pneumology Respiratory Diseases Clinic "Heckeshorn", Berlin, Germany), O. Pocuili, K. Inger, A. Renström (both Astrid Lindgren Children's Hospital, Karolinska Institutet and Karolinska University Hospital, Stockholm, Sweden) and A-S. Merritt (Karolinska Institutet, Centre for Allergy Research, Stockholm, Sweden).

The authors wish to thank the people who collaborated in the data collection, recruitment and instruction of technical personal during the ERS Congresses. Munich Congress: K.Ch. Bergmann (Charité, Berlin); Berlin Congress: T. Blum; and Vienna Congress: M. Dostal, L. Yassin, M. Urban, I. Firlinger (both Otto Wagner Hospital, Vienna, Austria) and K. Geyer. The tent in Berlin was made possible by the help and cooperation of the Deutsche Lungenstiftung (DLS), the Deutsche Atemwegsliga (AWL) and the Deutsche Gesellschaft für Pneumologie und Beatmungsmedizin (DGP).

The authors wish to thank P. Powell and A-M. Audley (ELF, Sheffield, UK) for their roles in the organisation and coordination of the study.

The ELF/ERS spirometry events (2004-2009) would not have been possible without the unrestricted generous financial support of Boehringer Ingelheim $\mathrm{GmbH}$ and Pfizer. We would also like to thank NDD Medizintechnik AG for the generous contribution of equipment and professional support.

\section{REFERENCES}

1 Celli BR, MacNee W, Augusti A, et al. Standard for the diagnosis and treatment of patients with COPD: a summary of the ATS/ERS position paper. Eur Respir J 2004; 23: 932-946.

2 Niederlander E. Cause of death in the EU. Statistics in focus population and social conditions. Eurostat (European Communities) 2006; 101: 1-12.

3 World Health Organization. World Health Statistics 2008. www. who.int/whosis/whostat/2008/en/index.html. Geneva, World Health Organization. Date last accessed: March 6, 2012.

4 World Health Organization report 2007. Global surveillance, prevention and control of chronic respiratory diseases. A comprehensive approach. Geneva, World Health Organization.

5 European Respiratory Society/European Lung Foundation. European Lung White Book. The First Comprehensive Survey on Respiratory Health in Europe. Loddenkemper R, Gibson GJ, Sibille Y, eds. Sheffield, European Respiratory Society Journals, 2003.

6 Buist AS, McBurnie MA, Vollmer WM, et al. International variation in the prevalence of COPD (the BOLD study): a population-based prevalence study. Lancet 2007; 370: 741-750.

7 Murtagh E, Heaney L, Gingles J, et al. Prevalence of obstructive lung disease in a general population sample: the NICECOPD study. Eur J Epidemiol 2005; 20: 443-453.
8 Lindberg A, Bjerg A, Rönmark E, et al. Prevalence and underdiagnosis of COPD by disease severity and the attributable fraction of smoking Report from the Obstructive Lung Disease in Northern Sweden Studies. Respir Med 2006; 100: 264-272.

9 Bednarek M, Maciejewski J, Wozniak M, et al. Prevalence, severity and underdiagnosis of COPD in the primary care setting. Thorax 2008; 63: 402-407.

10 Celli BR, Halbert RJ, Isonaka S, et al. Population impact of different definitions of airway obstruction. Eur Respir J 2003; 22: 268-273.

11 Hwang YI, Kim CH, Kang H-R, et al. Comparison of the prevalence of chronic obstructive pulmonary disease diagnosed by lower limit of normal and fixed ratio criteria. J Korean Med Sci 2009; 24: 621-626.

12 Silva GE, Sherrill DL, Guerra S, et al. Asthma as a risk factor for COPD in a longitudinal study. Chest 2004; 126: 59-65.

13 Viegi G, Matteelli G, Angino A, et al. The proportional Venn diagram of obstructive lung disease in the Italian general population. Chest 2004; 126: 1093-1101.

14 Arne M, Lisspers K, Ställberg B, et al. How often is diagnosis of COPD confirmed with spirometry? Respir Med 2010; 104: 550-556.

15 Damarla M, Celli BR, Mullerova HX, et al. Discrepancy in the use of confirmatory tests in patients hospitalized with the diagnosis of chronic obstructive pulmonary disease or congestive heart failure. Respir Care 2006; 51: 1120-1125.

16 Geijer RM, Sachs AP, Hoes AW, et al. Prevalence of undetected persistent airflow obstruction in male smokers 40-65 years old. Fam Pract 2005; 22: 485-489.

17 Stav D, Raz M. Prevalence of chronic obstructive pulmonary disease among smokers aged 45 and up in Israel. Isr Med Assoc J 2007; 9: 800-802.

18 Vandevoorde J, Verbanck S, Gijssels L, et al. Early detection of COPD: a case finding study in general practice. Respir Med 2007; 10: 525-530.

19 Zieliñski J, Bednarek M. Know the age of your lung study group. Early detection of COPD in a high-risk population using spirometric screening. Chest 2001; 119: 731-736.

20 Zielinski J, Bednarek M, Górecka D, et al. Increasing COPD awareness. Eur Respir J 2006; 27: 833-852.

21 Walters JA, Wood-Baker R, Walls J, et al. Stability of the EasyOne ultrasonic spirometer for use in general practice. Respirology 2006; 11: 306-310.

22 Menezes AMB, Perez-Padilla R, Hallal P C, et al. Worldwide burden of COPD in high- and low-income countries. Part II. Burden of chronic obstructive lung disease in Latin America: the PLATINO study. Int J Tuberc Lung Dis 2008; 12: 709-712.

23 Pellegrino R, Viegi G, Brusasco V, et al. Interpretative strategies for lung function tests. Eur Respir J 2005; 26: 948-968.

24 Quanjer PH, Tammeling GJ, Cotes JE, et al. Lung volumes and forced ventilatory flows. Report Working Party Standardization of Lung Function Tests, European Community for Steel and Coal. Official Statement of the European Respiratory Society. Eur Respir J 1993; 6: Suppl. 16, 5-40.

25 American Thoracic Society. Lung function testing: selection of reference values and interpretative strategies. Am Rev Respir Dis 1991; 144: 1202-1218.

26 Global Initiative for Chronic Obstructive Lung Disease. Update 2009. www.goldcopd.org. Date last accessed: April 10, 2012.

27 Stratelis G, Jakobsson P, Molstad S, et al. Early detection of COPD in primary care: screening by invitation of smokers aged 40 to 55 years. Br J Gen Pract 2004; 54: 201-206.

28 Castillo D, Guayta R, Giner J, et al. COPD case finding by spirometry in high-risk customers of urban community pharmacies: a pilot study. Respir Med 2009; 103: 839-845.

29 Van Durme YM, Verhamme KM, Stijnen T, et al. Prevalence, incidence, and lifetime risk for the development of COPD in the elderly. The Rotterdam study. Chest 2009; 135: 368-377. 
30 Soriano JB, Maier WC, Egger $\mathrm{P}$, et al. Recent trends in physician diagnosed COPD in women and men in the UK. Thorax 2000; 55 : 789-794.

31 De Marco R, Accordini S, Antò JM, et al. Long-term outcomes in mild/moderate chronic obstructive pulmonary disease in the European Community Respiratory Health Survey. Am J Respir Crit Care Med 2009; 180: 956-963.

32 Fletcher C, Peto R. The natural history of chronic airflow obstruction. BMJ 1977; 1: 1645-1648.

33 Svanes C, Sunyer J, Plana E, et al. Early life origins of chronic obstructive pulmonary disease. Thorax 2010; 65: 14-20.

34 Viegi G, Pedreschi M, Pistelli F, et al. Prevalence of airways obstruction in a general population: European Respiratory Society vs American Thoracic Society definition. Chest 2000; 117: Suppl. 2, 339S-345S.

35 Miller MR, Pedersen OF, Pellegrino R, et al. Debating the definition of airflow obstruction: time to move on? Eur Respir J 2009; 34: 527-528.
36 Langhammer A, Johnsen R, Gulsvik A, et al. Forced spirometry reference values for Norwegian adults: the Bronchial Obstruction in Nord-Trøndelag study. Eur Respir J 2001; 18: 770-779.

37 Johannessen A, Omenaas ER, Bakke PS, et al. Implications of reversibility testing on prevalence and risk factors for chronic obstructive pulmonary disease: a community study. Thorax 2005; 60: 842-847.

38 Celli B, Halbert RJ. CounterPoint: should we abandon FEV1/FVC $<0.70$ to detect airway obstruction? No. Chest 2010; 138: 1037-1040.

39 Enright P, Brusasco V. CounterPoint: should we abandon FEV1/ FVC $<0.70$ to detect airway obstruction? Yes. Chest 2010; 138: 1040-1042.

40 Bousquet J, Kiley J, Bateman ED, et al. Prioritised research agenda for prevention and control of chronic respiratory diseases. Eur Respir J 2010; 36: 995-1001.

41 MacNee W, Viegi G, Kamel N. New opportunities for respiratory research in Europe: FP7. Eur Respir J 2007; 29: 223-225. 